\title{
Perencanaan Pusat Kebudayaan dan Kesenian Kaltim Di Tenggarong dengan Penekanan Pada Akustik
}

\author{
Hatta Musthafa, ${ }^{1 *}$ Zakiah Hidayati, $^{2}$ M. Sutan Djaya Bunayya ${ }^{3}$ \\ ${ }^{1,2}$ Program Studi Arsitektur, Jurusan Desain, Politeknik Negeri Samarinda, Samarinda, Indonesia
}

Received: September 2021

Acepted: October 2021

Published: October 2021

\begin{abstract}
Indonesia has a diverse ethnic and cultural diversity that continues to grow in the lives of Indonesians. Each tribe and region have characteristic of various arts and become the pride of the region. Tenggarong is one of the district in Kutai Kartanegara regency that has a variety of arts. Kutai Kartanegara regency does not yet have the means to develop adequate creativity for its citizens to channel art expression and activities. Through Kaltim Cultural and Art Center is a container and facilities created for the artists, people and government of Kutai Kartanegara Regency in developing the potential of art and culture. This design process is created through several stages, namely the study of literature, observation and analysis of data that has been obtained so as to obtain the results of a design concept in accordance with the objectives. The east Kaltim Cultural and Art Centerwas created with Accoustic design concept and artificial lighting so that art performer and art connoisseurs can comfortably enjoy performaces and exhibitions. Kaltim Cultural and Art Center in Kutai Kartanegara Regency is expected to become an object of education, tourism, and creations that can become a new icon in Kutai Kartanegara regency especially Tenggarong district.
\end{abstract}

Key words: design, culture, acoustics.

\begin{abstract}
Abstrak
Indonesia memiliki beragam suku dan budaya yang memiliki keanekaragaman kesenian yang terus tumbuh dalam kehidupan masyarakat Indonesia. Setiap suku dan daerah memiliki ciri khas kesenian yang bermacam-macam dan menjadi kebanggaan daerah. Tenggarong merupakan salah satu kecamatan yang berada di kabupaten Kutai Kartanegara yang memiliki beranekaragam kesenian. Kabupaten Kutai Kartanegara belum memiliki sarana untuk pengembangan kreatifitas yang memadai bagi penduduknya untuk menyalurkan ekspresi dan aktifitas seni. Melalui Pusat Kebudayan dan Kesenian Kaltim merupakan wadah dan sarana yang diciptakan untuk para pelaku seni dan penikmat seni, masyarakat dan pemerintah Kabupaten Kutai Kartanegara dalam mengembangkan potensi seni dan kebudayaan yang ada. Proses desain ini diciptakan melalui beberapa tahap, yaitu studi literatur, observasi dan menganalisa data yang telah didapat sehingga mendapatkan hasil suatu konsep perancangan yang sesuai dengan tujuan. Pusat Kebudayaan dan Kesenian Kaltim diciptakan dengan penekanan akustik dan pencahayaan buatan agar pelaku seni dan penikmat seni bisa nyaman menikmati pertunjukan dan pameran. Pusat Kebudayaan dan Kesenian Kaltim di Tenggarong diharapkan menjadi suatu objek edukasi, wisata, dan kreasi yang mampu menjadi ikon baru di Kabupaten Kutai Kartanegara khususnya Kecamatan Tenggarong.
\end{abstract}

Kata kunci: Perencanaan, Kebudayaan, Akustik

\section{Pendahuluan}

Tenggarong sebagai kota kecamatan sekaligus ibukota Kabupaten Kutai Kartanegara memiliki ciri khas dibidang kesenian dan kebudayaan yang beragam dan majemuk, diantaranya adalah seni budaya asli Kabupaten Kutai Kartanegara yaitu seni musik, seni tari, seni teater dan juga seni kerajinan tangan

Sebagai Kecamatan yang memiliki beranekaragam kesenian, Tenggarong belum memiliki sarana untuk pengembangan kreatifitas yang memadai bagi penduduknya untuk menyalurkan ekspresi dan aktifitas seni yang

\footnotetext{
* Corresponding author : muhammadsutan67@gmail.com.
} 
dimilikinya. Oleh karena itu Tenggarong memerlukan adanya bangunan yang mendukung aktifitas kebudayaan dan kesenian yang bertemakan kebudayaan seni Kaltim, tradisional maupun modern, maka inilah yang melatar belakangi judul penelitian ini, yaitu Perencanaan Pusat Kebudayaan dan Kesenian Kaltim di Tenggarong dengan Penekanan pada Akustik.

\section{Permasalahan}

Pusat Kebudayaan dan Kesenian Kaltim diciptakan dengan penekanan akustik dan pencahayaan buatan agar pelaku seni dan penikmat seni bisa nyaman menikmati pertunjukan dan pameran.

\section{Kerangka Teori}

Perencanaan Pusat Kebudayaan dan Kesenian Kaltim dengan Penekanan pada Akustik adalah suatu wadah yang mendukung aktivitas kebudayaan dan kesenian yang diharapkan dapat mewadahi kegiatan pendidikan, pagelaran, sekaligus tempat wisata yang bertemakan kebudayaan seni Kaltim, tradisional maupun modern dan berfungsi sebagai tempat bertukar informasi tentang seni purba, tradisional dan modern di Tenggarong dan Kalimantan Timur,

\section{a) Persyaratan Ruang Akustik}

Akustik dalam arsitektur merupakan lingkup ilmu akustik yang mempelajari tentang penerapan aspekaspek akustik dalam suatu desain arsitektur, yang meliputi keseluruhan aspek perancangan. Ruang lingkupnya mulai dari yang terluas hingga yang terkecil, mulai dari desain lingkungan, desain tapak, desain bangunan, dan akhirnya desain ruang dalam (yang merupakan aspek paling utama) yang berguna untuk mendukung keseluruhan aspek akustik, agar dapat menghasilkan kuantitas serta kualitas akustik ruang secara optimal [1].

Halme [2] menyebutkan: Acoustics is a science and the first consideration to get a comfortable sound environment, bahwa akustik merupakan suatu ilmu dan merupakan pertimbangan pertama untuk mendapatkan lingkungan suara yang nyaman, sebagaimana pendapatnya: Jadi Tata Akustik merupakan pengolahan tata suara pada suatu ruang untuk menghasilkan kualitas suara yang nyaman untuk dinikmati, merupakan unsur penunjang terhadap keberhasilan desain yang baik karena pengaruhnya sangat luas dan dapat menimbulkan efek-efek fisik dan emosional dalam ruang sehingga seseorang akan mampu merasakan kesan-kesan tertentu.

Bunyi akan memantul apabila menabrak beberapa permukaan sebelum sampai ke pendengar sebagaimana menurut Mills (1986: 27) [3] : Reflected sound strikes a surface or several surface before reaching the receiver. Pemantulan dapat diakibatkan oleh bentuk ruang maupun bahan pelapis permukaannya. Permukaan pemantul yang cembung akan menyebarkan gelombang bunyi sebaliknya permukaan yang cekung seperti bentuk dome (kubah) dan permukaan yang lengkung menyebabkan pemantulan bunyi yang mengumpul dan tidak menyebar sehingga terjadi pemusatan bunyi

Untuk mencegah kurangnya energi suara, sumber bunyi harus dikelilingi oleh permukaan-permukaan pemantul bunyi seperti gypsum board, plywood, flexyglass dan sebagainya dalam jumlah yang cukup banyak dan besar untuk memberikan energi bunyi pantul tambahan pada tiap bagian daerah penonton, terutama pada tempattempat duduk yang jauh. Langit-langit dan dinding samping auditorium merupakan permukaan yang tepat untuk memantulkan bunyi.

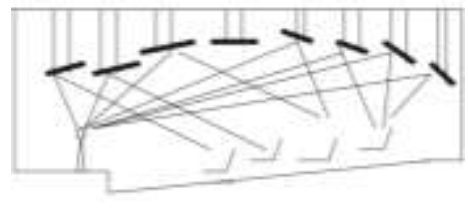

Gambar 1.

Penempatan langit-langit Pemantul [4]

Gambar di atas menjelaskan bahwa ketepatan dalam meletakkan langit-langit pemantul dengan pemantulan bunyi yang makin banyak ke tempat duduk yang jauh, secara efektif menyumbang kekerasan yang cukup. 
Hatta Musthafa, Zakiah Hidayati, M. Sutan Djaya Bunayya Perencanaan Pusat Kebudayaan Dan Kesenian Kaltim Di Tenggarong Dengan Penekanan Pada Akustik

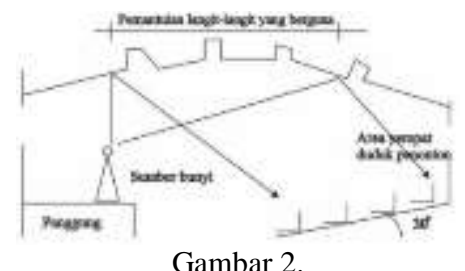

Bentuk plafond parallel yang dianjurkan [4]

Penonton harus berada di daerah yang menguntungkan, baik saat menonton maupun melihat pertunjukan, yakni berada pada area sumbu longitudinal.

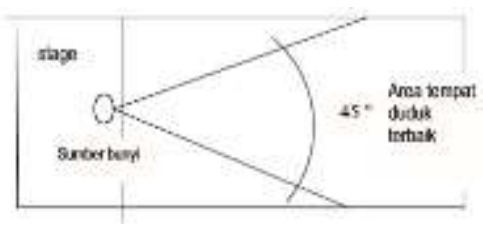

Gambar 3

Area sumbu longitudinal [4]

Area sumbu longitudinal merupakan area untuk pendengaran dan penglihatan terbaik, sehingga harus diefektifkan untuk tempat duduk. Agar pemain masih bisa leluasa dalam melakukan aksi panggungnya, maka rentang sudut yang masih bisa ditolerir $135^{\circ}$ dari sumber bunyi

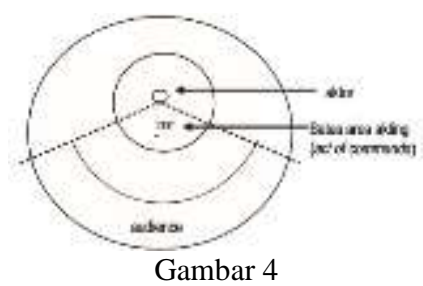

Limit Lingkar area penonton yang dapat dijangkau pemain [4]

Lingkar dengan sudut $135^{\circ}$ merupakan batas maksimal, karena lebih dari itu akan menambah ketidak leluasaan penampilan pemain saat melakukan pertunjukan.

1. Bentuk Ruang yang Tepat menurut Doelle [4] menyebutkan bahwa bentuk ruang juga mempengaruhi kualitas bunyi. Ada beberapa bentuk ruang pertunjukan yang lazim digunakan, yaitu :

a. Bentuk Ruang Empat Persegi merupakan bentuk tradisional yang paling umum digunakan. Keuntungan dari bentuk ruang empat persegi panjang memiliki tingkat keseragaman suara yang tinggi sehingga terjadi keseimbangan antara suara awal dan suara akhir. Kelemahan dari bentuk ini adalah pada bagian sisi panjangnya, karena menjadikan jarak antara penonton dengan panggung terlalu jauh. Solusi untuk permasalahan ini adalah dengan mempersempit area panggung dan memperlebar sisi depannya.

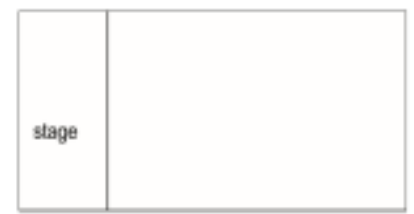

Gambar 5

Bentuk lantai empat persegi) [4]

b. Lantai bentuk Kipas Keuntungan lain dari bentuk ini dapat menampung penonton dalam jumlah banyak, menyediakan sudut pandang yang maksimum bagi penonton. Kelemahan dari bentuk ini 
yaitu permukaan dinding bagian belakang yang cekung merupakan bentuk yang tidak dianjurkan karena akan terjadi penyerapan suara yang terlalu tinggi di bagian belakang.

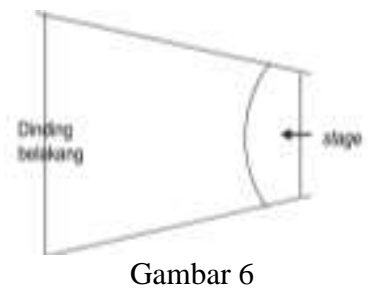

Denah Gedung Pertunjukan dengan bentuk kipas [4]

c. Ruang Bentuk Tapal Kuda merupakan bentuk yang memiliki keistimewaan karakteristik yakni adanya kotak-kotak yang berhubungan yang satu di atas yang lain. Walaupun tanpa lapisan permukaan penyerap bunyi pada interiornya, kotak-kotak ini berperan secara efisien pada penyerapan bunyi dan menyediakan waktu dengung yang pendek.

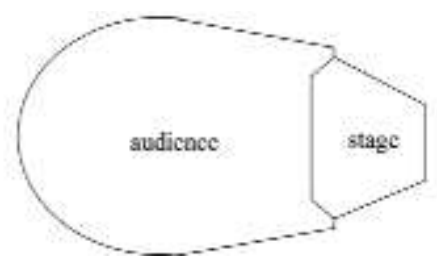

Gambar 7

Ruang berbentuk Tapal Kuda [4]

d. Bentuk Lantai Hexagonal di bawah ini dapat membawa penonton sangat dekat dengan sumber bunyi, keakraban akustik dan ketegasan, karena permukaan-permukaan yang digunakan untuk menghasilkan pemantulan-pemantulan dengan waktu tunda singkat dapat dipadukan dengan mudah ke dalam keseluruhan rancangan arsitektur.

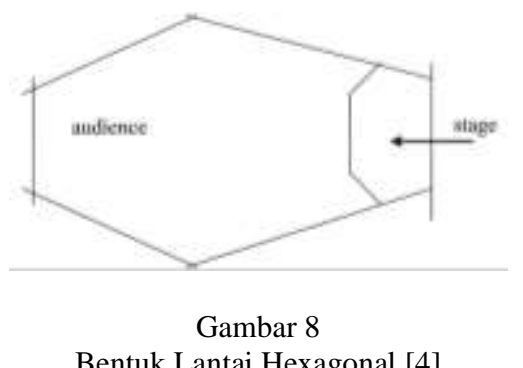

2. Distribusi Bunyi yang Merata. Energi bunyi dari sumber bunyi harus terdistribusi secara merata ke setiap bagian ruang. Untuk mencapai keadaan tersebut perlu diusahakan pengolahan pada elemen pembentuk ruangnya, yakni unsur langit-langit, lantai dan dinding, dengan cara membuat permukaan yang tidak teratur.

3. Ruang Harus Bebas dari Cacat-cacat Akustik. Cacat akustik yang biasa terjadi pada sebuah gedung pertunjukan yang tidak didesain dengan baik ada bebrapa jenis, yakni: Gema (echoes), Pemantulan yang Berkepanjangan (Long - Delayed (reflections), gaung, waktu dengung (reverberation time), pemusatan bunyi (hot spots), ruang gandeng (coupled spaces), distorsi, (whispering gallery). 
Hatta Musthafa, Zakiah Hidayati, M. Sutan Djaya Bunayya Perencanaan Pusat Kebudayaan Dan Kesenian Kaltim Di Tenggarong Dengan Penekanan Pada Akustik

\section{b) Pencahayaan Buatan}

Ada beberapa Teknik pencahayaan di ruang galeri dan ruang pertunjukan seperti :

1. Teknik Pencahayaan Aksen digunakan untuk memberikan efek khusus pada objek sehingga karakter objek yang diinginkan dapat ditonjolkan.

2. Teknik Pembayangan biasa digunakan di pameran-pameran, dimana cahaya digunakan untuk memaksimalkan karakter objek yang hendak dicapai.

\section{Metode Pengolahan Data}

Adapun langkah-langkah dalam metode pengolahan data adalah sebagai berikut: Membuat analisis perancangan, seperti; (analisis ruang, analisis tapak, analisis bangunan, analisis utilitas) membuat konsep perancangan, seperti; (konsep peruangan, konsep tapak, konsep bangunan, konsep utilitas) membuat transformasi desain membuat gambar kerja. membuat rencana anggaran biaya (RAB) \& rencana kerja dan syarat (RKS), membuat animasi

\section{Hasil dan Pembahasan}

\section{a) Lokasi Perencanaan}

Lokasi site berada di hook jalan antar Jl. Diponegoro dan Jl. Tepian Panji, site berada tepat di Kawasan Pasar Seni Tenggarong dengan Luasan site $3.149 \mathrm{~m}^{2}$.

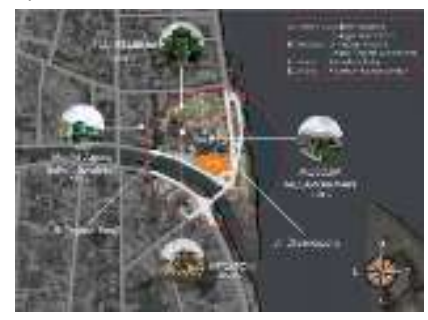

Gambar 9

Lokasi Perencanaan Site Terpilih (Penulis, 2020)

Dengan ketentuan Koefisien Dasar Bangunan seluas 60\%, maka luas daerah yang dapat dibangun pada lahan seluas $3.149 \mathrm{~m}^{2} \mathrm{~m}^{2}$ adalah $1.889 \mathrm{~m}^{2}$ Sedangkan, sisa dari lahan ini seluas 1,260 $\mathrm{m}^{2}$ akan dijadikan Ruang Terbuka Hijau dan tempat parkir sepeda motor, mobil dan bus.

Gubahan massa pada Pusat Kebudayaan dan Kesenian Kaltim adalah bentukan kubus

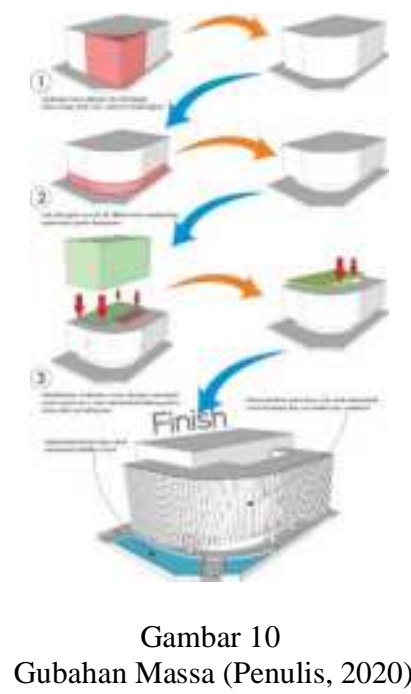




\section{b) Analisis Akustik}

Penyediaan analisis Akustik dapat mewujudkan azas-azas akustik yang menjadi tumpuan dalam merencanakan sebuah bangunan publik yang menerapkan akustika ruang yang baik.

1. Menerapkan Bentuk ruang Hexagonal agar dapat membawa penonton sangat dekat dengan sumber bunyi, keakraban akustik dan ketegasan,

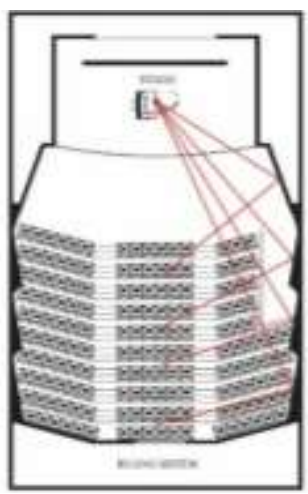

Gambar 11

Bentuk Ruang Hexagonal (Penulis, 2020)

2. Bentuk Panggung Proscenium, Panggung Proscenium yang disebut juga daerah pentas berada di salah satu ujung auditorium, dengan penonton yang mengamati lewat kerangka bukaan proscenium.

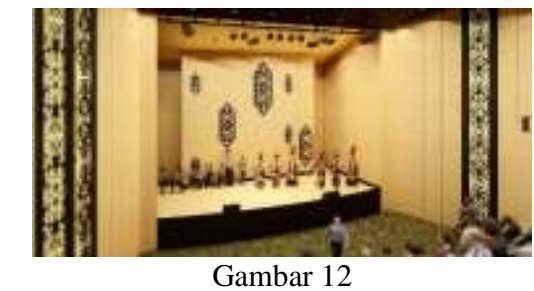

Bentuk Panggung Proscenium (Penulis, 2020)

3. Bentuk Lantai dan Langit-langit yang bentuknya teratur dapat menimbulkan pemantulan bunyi yang menguntungkan di dalam ruang pertunjukan. Waktu tunda yang pendek, dan terhindarnya dari pemutusan bunyi. Lantai miring yang disesuaikan dengan garis pandang dan pentulan bunyi dari langit-langit menimbulkan distribusi bunyi yang merata dan menguntungkan dalam segi akustik gedung.

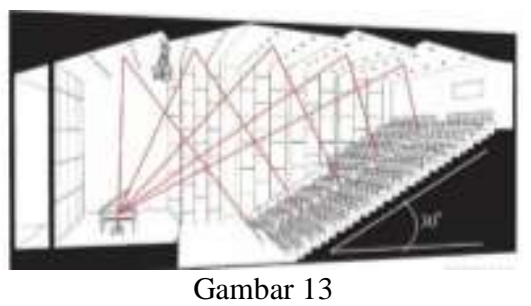

Bentuk Plafond dan Lantai (Penulis, 2020)

4. Material lantai pada ruang pertunjukan menggunakan material karpet dan acourete mat resin karena kemampuannya mereduksi getaran dan meniadakan bising benturan, Material Dinding dan plafon menggunakan panel kayu sebagai Material pemantul suara pada untuk memperoleh distribusi energi dan kekerasan yang cukup ke segala arah penonton. Pada bagian belakang penonton menggunakan bahan penyerap suara untuk menghilangkan gema. 
Hatta Musthafa, Zakiah Hidayati, M. Sutan Djaya Bunayya Perencanaan Pusat Kebudayaan Dan Kesenian Kaltim Di Tenggarong Dengan Penekanan Pada Akustik

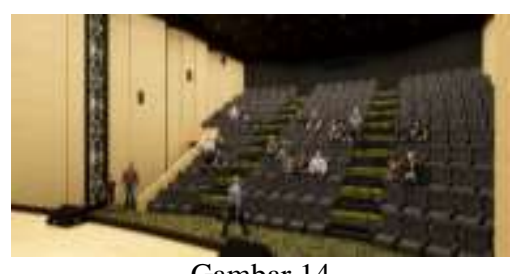

Gambar 14

Penerapan Material Akustik pada Ruang Pertunjukan (Penulis. 2020)

\section{c) Analisis Pencahayaan Buatan}

Pencahayaan pada Pusat Kebudayaan dan Kesenian Kaltim ini menggunakan pencahayaan buatan dan juga pencahayaan alami. Pencahayaan buatan terutama pada ruang pertunjukan dan ruang pameran.

\section{Ruang Pertunjukan}

Pencahayaan pada ruang pertunjukan digunakan lampu sorot pada panggung seperti; main light (cahaya berfungsi untuk menerangi panggung secara keseluruhan, foot light (lampu untuk menerangi bagian bawah panggung), wing light (lampu untuk menerangi bagian sisi panggung), front light (lampu untuk menerangi panggung dari arah depan), silouet light (lampu untuk membentuk siluet pada backdrop).

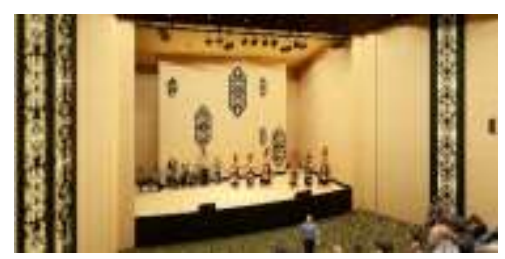

Gambar 15

Pencahayaan pada Panggung Pertunjukan. (Penulis. 2020)

\section{Ruang Pameran}

Teknik arah lampu pada ruang pameran menggunakan Spot Light dan Flood Light. Spot Light cocok diterapkan di karya seni 2D untuk menambah karakteristik dan juga untuk mempertegas tekstur sebuah karya, Flood Light cocok diterapkan di karya seni 3D tujuannya untuk menghilangkan efek bayang dan juga menambah tekstur pada karya seni.

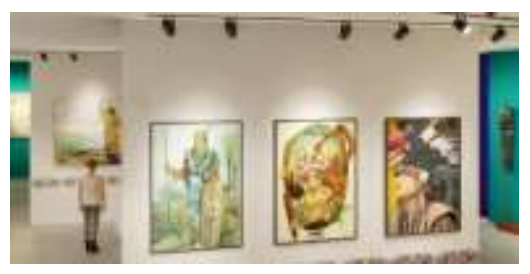

Gambar 20

Penerapan Teknik Spot Light pada Karya seni 2D (Penulis, 2020)

\section{d) Gaya Bangunan}

Tampilan bangunan Pusat Kebudayaan dan Kesenian Kaltim menggunakan gaya arsitektur Modern Kontemporer dengan penambahan ukiran kaltim pada fasad banguna, Konsep gaya bangunan pada tataruang dalam yang digunakan tetap dengan gaya Modern Kontemporer. 

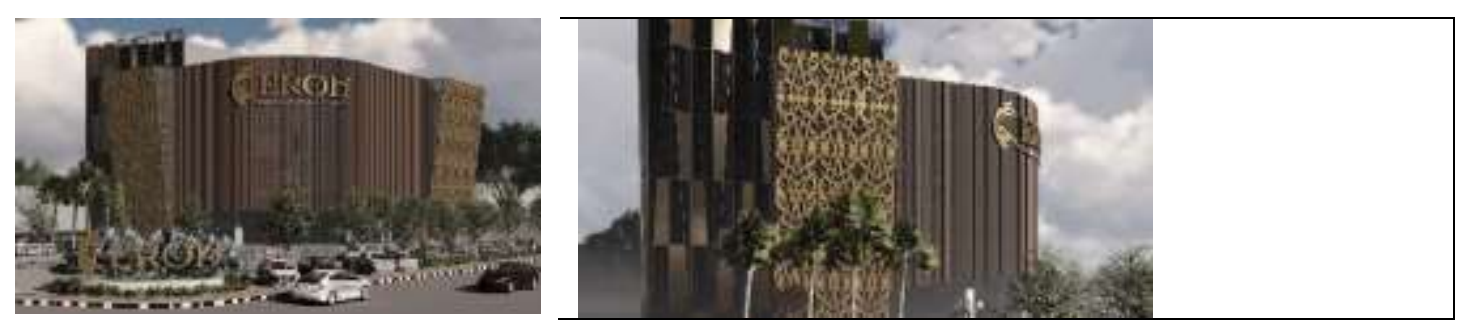

Gambar 21

Perspektif Pusat Kebudayaan dan Kesenian Kaltim (Penulis, 2020)

\section{Kesimpulan Dan Saran}

\section{a) Kesimpulan}

Berdasarkan hasil perencanaan dan pembahasan dapat disimpulkan bahwa Perencanaan Pusat Kebudayaan dan Kesenian Kaltim di Kecamatan Tenggarong dengan menerapkan akustika ruang dan juga pencahayaan buatan yang baik pada bangunan. Gedung Pusat Kebudayaan dan Kesenian Kaltim ini juga dipadukan dengan analisis tapak, memprhitungan iklim hingga penggunaan vegetasi yang akan diterapkan.

\section{b) Saran}

Dalam merancang sebuah bangunan harus memperhatikan kondisi lingkungan sekitar, kenyaman pengguna bangunan, dan sistem utilitas bangunan agar fungsi bangunan dapat berjalan dengan baik. Dan merancang sebuah tata ruang dalam bangunan diharapkan untuk memperhatikan elemen penting seperti pencahayaan buatan dan alami, penghawaan buatan dan alami, konsep warna dan material agar suasana tata ruang dalam yang diinginkan dapat tercipta dengan baik. 
Hatta Musthafa, Zakiah Hidayati, M. Sutan Djaya Bunayya Perencanaan Pusat Kebudayaan Dan Kesenian Kaltim Di Tenggarong Dengan Penekanan Pada Akustik

\section{Daftar pustaka}

1. Eviutami and C. M, Akustika Bangunan: Prinsip-prinsip dan Penerapannya di Indonesia. 2005, Jakarta Erlangga.

2. Halme, A., Space. 1991, Finlandia: Finnish Interior.

3. Edward D, M., Planning, London: Newness-Butterworth. 1976, London: Newness-Butterworth.

4. Doelle, L.E., Akustik Lingkungan. Jakarta: Erlangga. Vol. Erlangga. 1990: Jakarta. 